\title{
THE RELATIONSHIP BETWEEN EYE-PERCEPTION AND VOICE-RESPONSE IN READING
}

\author{
G. T. BUSWELL, \\ University of Chicago.
}

\section{Problem.}

In oral reading the eye always moves along the line of print in advance of the voice, at times keeping very far in the lead and at other times very little in advance. A mature reader tends to main. tain a comparatively wide average span between the eye and the voice, which at times may amount to the space occupied by seven or eight words. An immature reader, however, tends to keep the eye and voice very close together, in many cases not moving the aye from a word until the roice has pronounced it. Reading of this type becomes little more that a series of spoken words because there is no opportunity to anticipate the meaning in large units. An eye-voice span of considerable width is necessary in order that the reader may have an intelligent grasp of the material read, and that he may read it with good expression. If words are encountered which are spelled alike but pronounced differently, such as "read" (present tense) and "read" (past tense), the correct pronunciation and meaning cannot be determined in many cases until the eye has observed the context by looking ahead. The need for a wide eye-voice span is also emphasized when marks of punctuation are encountered. The failure of immature readers to respond to a question mark by a rising inflec tion of the voice is clear evidence that a narrow eye-voice span has kept them unaware of its presence until it is too late to modify their expression.

In order to determine more fully and accurately the nature of the eje-voice span an investigation was organized to cover a series of problems which were involved. This article presents a bricf sum. mary of the experiments, a complete report of which has been made in a separate monograph.'

The experiments were grouped into three main divisions. In the first (a) an analysis was made of the eye-voice span showing the differences in the width of the span in the different grades and in the high school, and (b) the variations in the width of the span in dif. ferent parts of the sentence. In both (a) and (b) the results were

'Buswell, G. T. An Eaperimental Study of the Eye-Voice Span in Reading. "Bupplementary Educt 
grouped to show separately the characteristics of pupils with mature and immature reading habits. Following this, (c) a comparison was made to show the relationship of the width of the eye-voice span to rate of reading, number of fixations per line, and regressive movements.

In the second division (a) a very detailed analysis of the eycvoice relationship was made, showing the exact position of the eye and voice at each fixation pause, and exhibiting the variations in the width of the eye-voice span in the reading of different parts of a passage by the same individual. These results were used (b) in an attempt to explain the cause of the occasional very long fixation pauses which appear in reading records.

The third division of the investigation made use of a test device, consisting of a paragraph containing words spelled alike but pronounced differently, by which the eye-voice span in oral reading was studied in relation to the recognition of meaning in silent reading.

\section{Method.}

The apparatus and general method of the investigation were the same as used in a number of researches in the Chicago laboratory, and have been described in detail in a monograph by C. T. Gray.' Briefly stated, the method consisted of photographing a beam of light generated by an arc lamp, reflected first to the cornea of the eye from silvered glass mirrors, and then from the cornea through a lens to a moving film. The pencil of light changes its direction with each movement of the eye. As the subject reads a,photograph is made on the moving film in the form of a sharply focused line The shifts in this line record the movements of the eye. An elec. trically driven tuning fork, with a vibration rate of fifty per second, is mounted in the path of the beam of light in such a way that the light is intercepted at each vibration. These vibrations produce on the film a line of dots rather than a solid line, each dot representing a time of exactly one-fiftieth of a second. Since the film is moving continuously in the vertical plane, the record shows a vertical line of dots while the eye is fixated in a single position, and a short horizontal line when the eye is in motion in a horizontal or oblique

2Gray, C. T. Types of Reading Abilty as Echibited Throwgh Tests and Laboratory Eoperinents. "Supplementary Educational Monographs," Vol. I, No. 5. Chicago: The University of Chicago, 1917. Pp. $83-90$. 
direction. By means of such a record the exact location of each fixa tion can be determined. In order to get a record of the voice the photograph was supplemented by a dictphone record of the oral reading, taken for each subject at the time the photograph was made. By means of an electrical device the dictaphone and film records were synchronized, showing the relative position of the eye and voice at different places in the reading.

Photographs taken of the readings of 54 subjects selected as follows. Two good and two poor readers were selected from each of the elementary grades above the first, on the basis of scores made in W. S. Gray's Oral Reading Paragraphs. Three good and threc poor readers were selected through the co-operation of the English department from each of the four high school classes. Six adult college students were selected at random and ranked into two groups, one better in reading than the other. The entire group of subjects, therefore, included twenty-four from the elementary school, twenty-four from the high school, and six college students, each grouping being made up of equal numbers of good and poor readers.

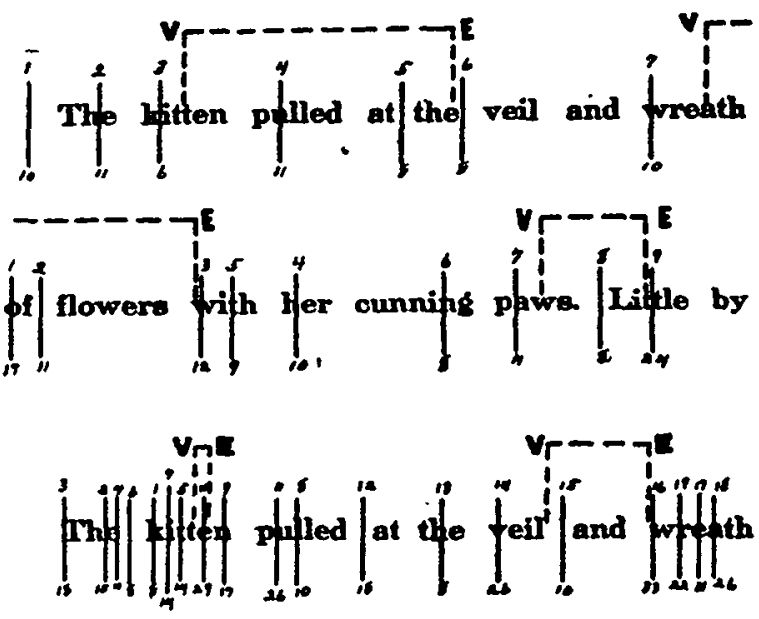

PLATE I.

First two lines show reading record of a cood reader from the fourth grade. Thitd line abows reading record of $a$ poor reader from the aecond Erade.

Plate I shows sections from two typical records which will serve to illustrate the method. The short vertical lines crossing the lines of print indicate the positions of eye-fixations. The serial numbers above the verticals indicate the order of the pauses; the numbers at 
the lower end of the vertical lines give the duration of the fixation in fiftieths of a second. The brackets of broken lines indicate the relative positions of the eye and voice. For example, in the first line when the voice was pronouncing the word "kitten" the eye was fixated just after the word "the." The letters "V" and "E" show the corresponding positions of the voice and eye respectively, the width of the eye-voice span at this position being 17 letter-spaces. The third line of Plate I shows the record of a second grade reader with very immature reading habits. The eye-voice span for this subject is very narrow.

\section{Analysis of Eye-Voice Relationship.}

The first division of the investigation made an analysis of the eyevoice relationship and a comparison of the eye-voice span with other factors of the reading process. The results may be summarized ds follows :

1. A positive correlation was shown between a wide eye-voice span and mature reading habits. The average span for the good readers is greater than that for the poor readers in every school grade. The average width of the span for the good readers in the elementary grades is greater than that of the poor readers by 58 per cent; for the subjects from the high school it is greater by 36 per cent.

2. Width of eye-voice span has a positive correlation with rate of reading, as shown in Table I which follows.

TABLE I.

Relation of Eye- Yoice Span Reaping to Rate-All Burjects.

Number of

Subjects.

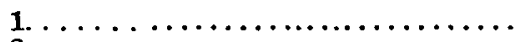

$2 . \ldots \ldots \ldots \ldots \ldots \ldots \ldots \ldots \ldots \ldots$

$10 . \ldots \ldots \ldots \ldots \ldots \ldots \ldots \ldots \ldots \ldots \ldots \ldots \ldots$

$29 . \ldots \ldots \ldots \ldots \ldots \ldots \ldots \ldots \ldots \ldots$

12

3. A negative correlation is shown between width of eye-voice span and number of fixations per line. As the span increases in width the number of fixations per line decreases.

The three results above mentioned merely confirm what one would naturally expect to find true. 
4. The development of the eye-voice span does not show a consistent increase from grade to grade, but is very irregular. On the whole there is a development in width of span throughout the grades, the high school average being greater than that for the elementary grades, and the adult average greater than that for the high school. However, some good readers from the elementary grades have a greater span than many of the high school subjects. The results show that some readers develop an eye-voice span by the end of the fifth grade which is greater than the average span for all the good readers from the high school.

5. Little correlation was found between width of eye-voice span and position in the line. However, when studied in relation to position in the sentence a marked correlation was discovered. Table II shows the average eye-voice span, in number of letter spaces, for positions at the beginning, within, and at the end of sentences.

TABLE II.

aferage Eye-Voice Span at the Beoinning, Within, and at the End of SENTENCE-AIL SUBJECTs.

\begin{tabular}{|c|c|c|c|}
\hline Subjects. & $\begin{array}{l}\text { Beginning } \\
\text { of Sentence. }\end{array}$ & $\begin{array}{l}\text { Within } \\
\text { Sentence. }\end{array}$ & $\begin{array}{c}\text { End } \\
\text { of Sentence. }\end{array}$ \\
\hline \multicolumn{4}{|l|}{ Elementary subjects: } \\
\hline Good readers........... & 16.1 & 14.8 & 8.4 \\
\hline Poor readers............. & 8.6 & 8.5 & 7.9 \\
\hline 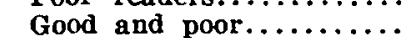 & 12.3 & 12.1 & 8.1 \\
\hline \multicolumn{4}{|l|}{ High-school subjects: } \\
\hline 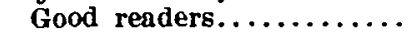 & 16.6 & 16.2 & 13.3 \\
\hline Poor readers............. & 12.9 & 11.0 & 10.5 \\
\hline Good and poor............. & 14.7 & 13.6 & 11.9 \\
\hline \multicolumn{4}{|l|}{ Adult subjects: } \\
\hline Good readers............ & 23.5 & 18.6 & 14.0 \\
\hline Poor readers............. & 17.7 & 10.8 & $\mathbf{1 1 . 3}$ \\
\hline Good and poor............ & 20.6 & 14.7 & 12.6 \\
\hline \multicolumn{4}{|l|}{ All subjects: } \\
\hline 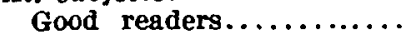 & 18.7 & 16.5 & 11.9 \\
\hline Poor readers............... & 13.1 & 10.4 & 9.9 \\
\hline Good and poor............ & $\mathbf{1 5 . 9}$ & 13.4 & 10.9 \\
\hline
\end{tabular}

An examination of these data reveal two conspicuous facts: first, that the width of the eye-voice span is different at various positions in a sentence, and second, that the good and poor readers do not exhibit these differences in the same fashion. The eye-roice span is found to be relatively wide at the beginning of a sentence and rela. tively narrow at the end.

The fact that the eye-voice span varies with the position in th? sentence is of considerable significance. If the span varied only 
with the position in the line, the determining factors would be only mechanical, and would be determined by the printed form of the selection. The control of the span in that case would be a matter of the mechanics of book construction, and would be independent of any teaching factor. But if the span varies with the position in the sentence, it is evident that the content of the meaning is recognized, and that the eye-voice span is determined by thought units rather than by printed line units.

For all three classes of subjects there is agreement among the readers in that a wide eye-voice span occurs at the beginning of a sentence. The situation at the beginning of a sentence is different from that of any other position. After one has started to read, the meaning of the thought covered will carry him along to some extent, and will enable him to anticipate what is coming. At the beginning of a sentence there is no sequence of words to give one the cue to the content of the new thought. The only way to get this is to look ahead until the meaning of the sentence is partially recognized, and the kind of vocal expression needed is made clear. The good readers recognize this need for a wider span at the outset and inbibit the voice reaction until the eye has gained a considerable lead. The poor readers in the grades above the elementary school have also learne'l this, but evidently those in the elementary school are not mature enough in reading to recognize any special difficulty at the beginning of a sentence. Instead of making a relatively longer span, they react to the situation by a relatively shorter one. They begin to rear as soon as they see the sentence, and have not learned to inhibit their reading until the eye has taken in a larger unit of meaning. This difficulty could be easily corrected by a little training in class which, would teach the pupils to wait before starting to read until they get a larger unit of thought.

The evidence of all subjects agrees that there is a shorter span at the end of a sentence. The good readers have a relatively shorte. span than the poor readers. The explanation of this shorter span goes back again to the fact that the sentence is the large unit of meaning. When the eye reaches the end of this unit it modifies its movements according to the meaning recognized and the voice catches up before beginning the new thought. In order that the voice shall express the thought clearly, a pause is necessary at the end of the sentence. This pause gives the eye ample opportunity for a large 
eye-voice span before it is time to commence the next sentence. $A$ poor reader pays less attention to the sentence as a unit of meaning. This is especially true of younger children who are very immature readers. For them the whole process is a more or less monotonous repetition of words as they are encountered. The eye moves along at a regular rate and the voice follows. The end of a sentence creates no special disturbance, for it is passed over with little attention. Consequently there is little change in the eye-voice span. The data for the poor readers from the elementary school would seen to indicate that some such situation exists. There is little variation in the width of the span for any position in the sentence. If the variation in the eye-voice span at the beginning and the end of a sentence makes possible a greater emphasis on meaning, the lack of such a variation may account for the fact that the subjects showing such lack are classed as poor readers.

\section{Continuous Relationship of Eye and Voice.}

A comparison of the width of the eye-volce span as measured at different positions in a paragraph showed a considerable variation from point to point in a selection read by a single subject. In order to get more complete data on the continuous relationships of the eye and voice, a very detailed analysis was made of the records of a number of subjects showing the exact relationship of the eye and voice at each word in the selection. Plate II gives a section of a typical record treated by this kind of analysis. The selection has been duplicated in parallel lines in order to show the eye-voice rela tionship more clearly. The upper line of the pairs may be called the eye line, and shows the position and duration of eye-fixations in the same manner as in the previous plate. The lower line of the pairs may be called the voice line. The diagonal lines connect the posi tions of the eye and voice for every fixation.

In the record shown in Plate Ir, the positions of the eye and voicc were synchronized first as the voice was pronouncing the word "two" in line 1. As the roice began to pronounce "two" the eye was fixated on the last letter of the word "were," which is the fifth fixation in the line. These two points may therefore be taken as a base of measurment for the determination of the relative positions of the eye and voice at succeeding words and fixations. It will be observed by reference to the plate that $34(20+14)$ fiftieths of a second elapsed 

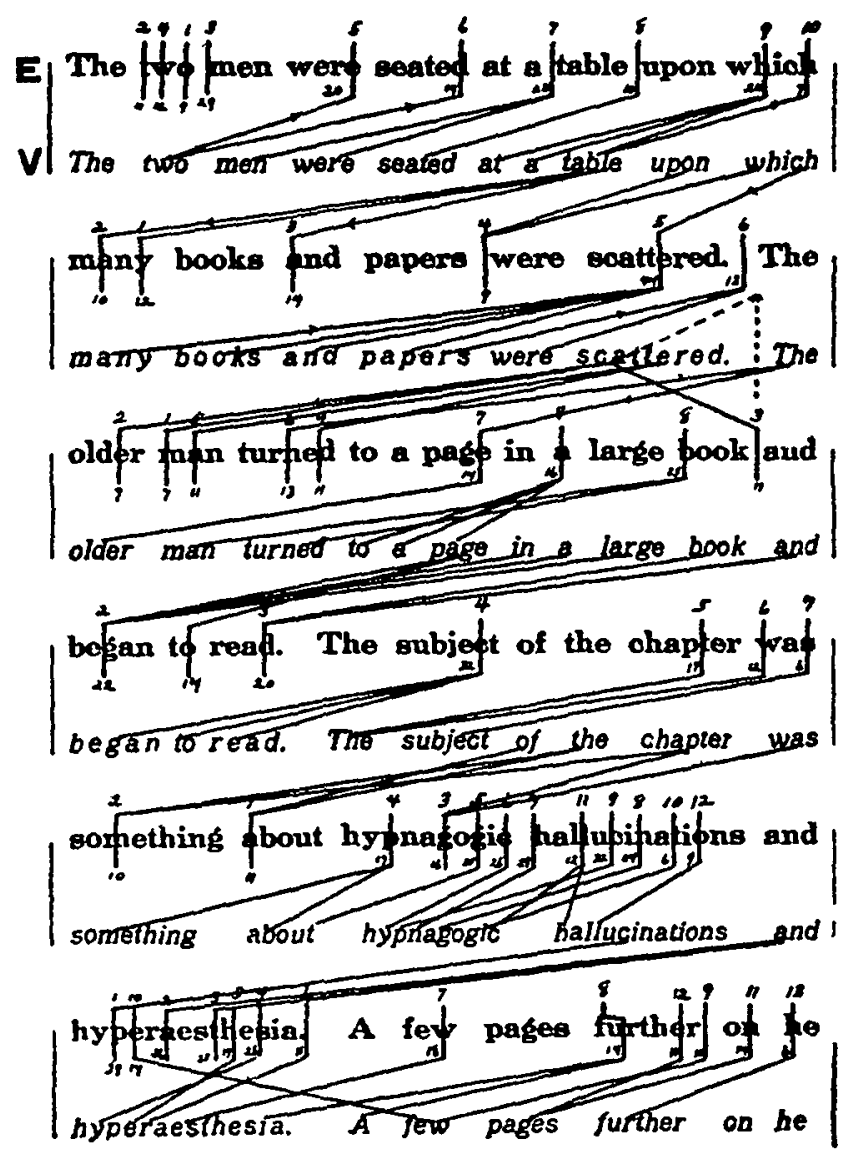

PLATE II.

Showing continuous eye-voice relationshlp of a good reader from the high school.

during fixations 5 and 6 . The time on a stop-watch showed that at a point 34 fiftieths of a second after beginning to pronounce " $t w o$," the roice had not begun to pronounce the next word, indicating that fixations 5 and 6 were both made during the time used by the voice in reading the word "two." From fixation 5 to the end of fixation 7 a time of $57(20+14+23)$ fiftieths of a second elapsed. The record from the stop-watch and the dictaphone showed that during the interval from 34 fiftieths of a second to 57 fiftieths, the voice had pronounced the words "men" and "were." By a continuation of this 
form of analysis the relative positions of the eye and roice were located for every word and every fixation.

Two characteristics of reading are apparent from this type of analysis. The first is the elastic nature of the eye-voice relationship. The width of the spau is evidently varied according to the demands of the content of the material. When the difficult words in the last two lines are encountered there is a very marked morlifica tion of the eye-voice span.

A second type of result, which was indirectly found, is an apparent relationship between the length of fixation pauses and difficultics in reading. The average duration of a fixation pause for the subject shown in Plate II is $\mathbf{1 2}$ fiftieths of a second. If the three difficult words are again observed it will be seen that most of the fixations upon these words are much longer than the average. This suggested that an explanation of the occurence of long fixations might be found in the content of the reading selection.

In order to test this possibility a study was made of all fixations which were longer than 20 fiftieths of a second in the records of nine teen subjects. The readings of these nineteen subjects showed a total of 259 fixations which were over 20 fiftieths of a second in length. The selection which these subjects read contained ninety words. If the long fixations simply occurred at random there should be an average of 2.9 for each word in the paragraph. The point of interest is that the long fixations are not distributed in a randora fashion with 2.9 falling on each word, but that they occur much more frequently on certain words than on others. The greatest number of long fixations fall upon the words "hyperaesthesia," "hypnagogic," and "hallucinations," these words receiving 31,22 , and 16 fixations respectively.

The interpretation of such results must be related to the development of reading habits. The records of the elementary subjects, whose reading habits are still inmature, show that long fixations are frequent and occur all through the selection. Evidently long fixations are characteristic of immature types of reading. The high school and adult subjects represent more mature readers. In general they have outgrown the long fixation habits. However, when words of special difficulty or difficult phrases are encountered they return immediately to the primitive type of habits characteristic of the immature reader. 


\title{
The Eye-Voice Span and the Recognition of Meaning.
}

The significant factor about a wide eye-voice span is that it pro vides a wide onit for the interpretation of meaning before the voice reaction takes place. In order to test this factor a paragraph was constructed containing a number of words which are spelled alikc but may be pronounced differently. The section used is shown below, with the test words italicized.

\begin{abstract}
The boys' arrows were nearly gone so they sat down on the grass and stopped hunting. Orer at the edge of the woods they saw Henry makIng a bono to a little girl who was coming down the road. She had tears in her dress and also tears in her eyes. She gave Henry a note which he brought over to the group of young hunters. Read to the boys it caused great excitement. After a minute but rapid examination of their weapons they ran down the valley. Does were standing at the edge of the lake making an excellent target.
\end{abstract}

The paragraph is so constructed that the meaning of the test words is not evident until the next few words in the sentence are read. For example, in line three, the word "tears" is ambiguous until the word "dress" is reached. The hypothesis in regard to the eye-voice span is that no error will be made in the reading if the span is wide enough to enable the reader to take in the word "dress" before pronouncing the word "tears." If the span is not wide enough to do this there is a strong probability of error. By varying the distance between the test words and the part of the sentence which qualifies it, a rough measure of the width of the eye-voice span can be secured. If this hypothesis is correct, subjects having a wide eye-voice span should make fewer errors than those whose span is narrower. The trial of the paragraph with a group of subjects showed the hypothesis to be correct.

Photographs of the oral reading of the test paragraph brought ont two facts clearly. The first is that difficulties in the recognition of meaning are reflected in the eye movements by characteristic types of confusion. This was demonstrated by a comparison of the dictaphone and photographic records. The second fact is that subjects having a wide eye-voice span have less difficulty with such material than subjects with a narrow span. 
Photographs were also taken of the silent reading of the test paragraph. The same characteristic eye-confusions occur at some of the test words as occurred in the oral records. Evidently there is in silent reading an eye-recognition span which is similar to the eyevoice span in oral reading. Comparisons of oral and silent records show that whenever difficulties with the test words are experienced, the same types of confused eye movements occur. Since subjects with a wide eye-voice span have fewer difficulties with the oral reading of such material than subjects with a narrower span, it suggests that training for a wide eye-voice span would carry over into silent reading habits.

It has been pointed out that when difficulties are encountered in oral reading the eye-voice span is immediately reduced to a primitive form. The same thing occurs in silent reading. Silent reading records showed that when the difficult words in the test paragrapin were encountered, the eye returned to the word causing the difficulty just as it returned to the position of the voice in oral reading. If the difficulty in getting the meaning in silent reading is sufficiently great, there is a reversion not only to the habit of bringing the eye back to the location of the recognition of meaning, but also to the most primitive habit of silently pronouncing the words. This reinstates the most primitive form of reading where the eye, the voice, and the meaning proceed together.

The development of the reading process may be traced through three stages. First, the most primitive or immature stage of oral reading where the eye, the voice, and the meaning are all focused at the same point. Such a stage is illustrated by the reading of one of the second grade subjects where the average eye-voice span was less than the width of the average word in the selection. Second, a more mature stage of oral reading where there is a considerable span between the eye and the voice, with the center of attention near the eye, the voice reaction occurring in a semi-automatic fashion. Third, the stage of silent reading where the reader is entirely relieved of any attention to the voice and where the entire attention can be given to the eye and the meaning, making possible the development of a much higher degree of proficiency. 